\title{
The Domestic Migration Stress Questionnaire (DMSQ): Development and Psychometric Assessment
}

\author{
Xinguang Chen \\ University of Florida, United States \\ E-mail: jimax.chen@phhp.ufl.edu \\ Bin Yu (Corresponding Author) \\ University of Florida, United States \\ E-mail: byu@phhp.ufl.edu
}

Jie Gong

Wuhan Center for Disease Prevention and Control, China

E-mail: gongjie@whcdc.org

Jing Zeng

Wuhan Center for Disease Prevention and Control, China

E-mail: 8534219@qq.com

Karen Kolmodin MacDonell

Wayne State University, United States

E-mail: kkolmodin@med.wayne.edu

Received: January 26, 2015 Accepted: April 3, 2015 Published: April 4, 2015

doi:10.5296/jsss.v2i2.7010 URL: http://dx.doi.org/10.5296/jsss.v2i2.7010 


\section{Abstract}

The growing trend in domestic migration needs empirically based instruments to assess stresses experienced by millions of migrants. We developed the Domestic Migration Stress Questionnaire (DMSQ), the first instrument for measuring domestic migration stress, with reference to published instruments for assessing international migration related stresses. The DMSQ is the first tool designed to measure domestic migration stress. It consists of 16 items and organized into four subconstructs (separation from origin, rejection in the destination, lack of self-confidence and maladaptation). Rigorous psychometric assessment using data collected among rural-to-urban migrants in China $(n=77$, mean age $=24.34, \mathrm{SD}=5.85)$ indicated that DMSQ has a clear four-factor structure, excellent reliability (Cronbach alpha $=.93$ ), and adequate validity (significantly related to Perceived Stress Scale score, and predicted an array of stress-related mental health symptoms). The DMSQ provides an instrument much needed for research to assess levels of stress associated with domestic migration. Additional studies are needed to assess its utilities in other places outside of China and to assess longitudinal characteristics of the instrument.

Keywords: Domestic migration stress, Psychometric assessment, Rural-to-urban migration, Mental health

\section{Introduction}

\subsection{Domestic Migration and Stress}

In an era of increased globalization, population migration is becoming more and more frequent (Al-Rodhan \& Stoudmann, 2006; Berry, Phinney, Sam, \& Vedder, 2006; Yu, Chen, \& Li, 2013). Much like the uneven-paced development and economic inequalities that underlies the international migration (Chen, 2014; Wong \& Song, 2008), the increasing domestic migration reflects the unevenly-paced development and great difference in levels of economy and wealth within a country. Domestic migration is now being observed in many developing countries across the globe (De Haan, 1997; Ma, Liaw, \& Zeng, 1997; Shen, 1995; Yadava, 1987). We might expect that along with this rapid and unevenly-paced development, domestic migration will continue to increase, as more and more people leave their home, often a less developed area, and relocate to more developed and more prosperous areas to pursue new opportunities.

Migration brings with it the promise of a new and better life and increased opportunities. However leaving home, migrating to a new place, adapting to new neighborhoods and lifestyles, adjusting to different work environments, all could be very stressful (Berry et al., 2006; Ramirez, Garcia-Garcia, \& Peralta-Ramirez, 2013; van der Ham, Ujano-Batangan, Ignacio, \& Wolffers, 2014; Yu et al., 2013). Much has been documented regarding stresses associated with international migration (Ramirez et al., 2013; Sanou et al., 2014; Sirin, Ryce, Gupta, \& Rogers-Sirin, 2013), whereas few studies have investigated potential stressors for domestic migration. For studies that focus on domestic migration and health (Chen et al., 2004; Chen, Stanton, Li, Fang, \& Lin, 2008; Chen et al., 2009; Lin et al., 2005), few, if any have assessed stressors that are specifically related to domestic migration. We argue that empirically-based tools are needed to understand stressors faced by domestic migrants and to promote healthy migration. Thus the main purpose of this study is to develop a scale designed 
to measure domestic migration stress.

\subsection{The process of Migration}

Leaving the place of origin marks the beginning or "genesis" of the actual migration, though this may or may not be preceded by extensive planning and preparation (Gui, Berry, \& Zheng, 2012). Stressors during the genesis step include leaving familiar ambiance and separation from families, relatives and friends (Tomas-Sabado, Qureshi, Antonin, \& Collazos, 2007).Responses to these stressors often include feelings of homesick, anxious for family and friends to visit, and missing the familiar ambiance in hometown (Tomas-Sabado et al., 2007).

Settlement at the new destination is the next step and marks the beginning of the process of integrating into the new environment, neighborhood, community and people. Stressors at this stage may be internal or external. External stressors may include social stigma and rejection, opportunity deprivation for jobs, marginalization and social isolation. Internal stressors often include low self-confidence and low social competence (Tomas-Sabado et al., 2007; Yu et al., 2013; Yu et al., 2014). Migrants can do little regarding the external stressors, but the internal factors may be particularly important. There is evidence that high levels of self-confidence and competence may protect migrants from even severe, ongoing stressors associated with migration and settlement processes; while migrants with low levels of confidence and competence may be less resilient even in the face of acute and relatively less severe stressors (Wong \& Chang, 2010; Wong, Lam, Yan, \& Hung, 2004).

The final step in the migration process is the sequel stage. This stage involves establishing a new life at the destination. During this period, maladaptation, or difficulty to adapt to the expectations and realities of the new surroundings and location is the main source of stress. Stressed migrants are more likely to report feeling that life in their new location is markedly different from what they had anticipated prior to migrating. They are also more likely to experience difficulty getting used to the new people and environment in the new location and to perceive great difficulty achieving future life and career success (Berry, 1997; Tomas-Sabado et al., 2007).

\subsection{Instruments for Measuring Migration Stress}

We did not find an empirical instrument for measuring domestic migration stress in a recent search of the literature. However, tools do exist for measuring international migration stress and are widely available. Typical examples include: Index of Life Stress (ILS) (Yang \& Clum, 1994), the Demands of Immigration Scale (Aroian, Norris, Tran, \& Schappler-Morris, 1998), Multidimensional Acculturative Stress Inventory (MASI) (Rodriguez, Myers, Mira, Flores, \& Garcia-Hernandez, 2002), Hispanic Stress Inventory for Immigrants (HIS-I) (Cavazos-Rehg, Zayas, Walker, \& Fisher, 2006), the Barcelona Immigration Stress Scale (Tomas-Sabado et al., 2007), Multidimensional Acculturative Stress Scale (MASS) (Jibeen \& Khalid, 2010).

Even though these instruments were not devised for measuring domestic migration stress, we used them in the process of developing our new tool, particularly the stressful events related to migrants in general.

All the instruments listed above focus on a number of key stressful events related to migration at various migration stages, including leaving home, confronting and fighting with prejudice, stigma, rejection, marginalization, isolation and loneliness at the destination, 
lacking self-confidence to adjust to the new environment (Cavazos-Rehg et al., 2006; Jibeen \& Khalid, 2010; Rodriguez et al., 2002; Tomas-Sabado et al., 2007), and difficulties in fitting into the local society once settling at the destination (Tomas-Sabado et al., 2007). For the present study, we utilized most of these stressful events and adapted them for assessing domestic migration stress. Stressors related cultural differences in these instruments (language difficulties, race/ethnicity related stigma) are not considered because they are not relevant to domestic migration.

\subsection{Purpose of this Study}

In this study, we developed the Domestic Migration Stress Questionnaire (DMSQ).Multiple instruments have been developed to measure international migration and stress, but the instrument developed here is the first to extend that work to measure domestic migration.

\section{Methods and Materials}

\subsection{Participants and Sampling}

We evaluated the proposed DMSQ among rural-to-urban migrants in China which has experienced rapid growth of domestic migration beginning in the 1980s (Chen et al., 2009; Shen, 1995). Participants were recruited in 2011 from Wuhan, the capital city of Hubei Province, China. Wuhan is located in central China and has a total population of 9.2 million and a per capita GDP of $\$ 10,000$ (Statistical Bureau of Wuhan, 2012). The estimated number of rural-to-urban migrants in Wuhan is approximately 1.5 million (National Statistical Bureau, 2012; Xu, 2006).

The participants were sampled at Wuhan Center for Disease Prevention and Control (CDC) where rural migrants in the city are required to come for an annual physical check-up as part of their urban employment requirements. These migrants spent an average of 1-3 years in Wuhan. This time frame is largely representative of the rural migrant population in the city in general. Participants were recruited in the waiting room at the Physical Check-up Clinic of Wuhan CDC. Recruitment was completed by trained investigators. Among the 86 individual migrants approached, 77 (90\%) agreed to participate by signing the informed consent and completing the survey questionnaire.

\subsection{Scale Development}

We developed the instrument DMSQ through a team effort led by the first author of this paper. Following the review of the literature and existing migration stress scales, the research team collaborated to develop, review, and revise scale items, pilot test the measure, and finalize the scale. The finalized DMSQ consists of 16 items and four subconstructs, with four items per subconstruct (see Table 2 for details). The four subconstructs are (1) Separation from the place of origin, assessing stressful responses associated with leaving home; (2) Rejection in the destination, measuring the perceived discrimination, isolation, and opportunity deprivation; (3) Lack of self-confidence, evaluating stresses due to the lack of confidence and competence in adapting to the new environment; and (4) Maladaptation, measuring stressful and frustrated feelings associated with difficulty or failure to adapt to the new environment. Each item is comprised of a statement about a stressor or a stressful response any migrant may experience. A5-point Likert scale was used to assess how frequently these events are experienced with $1=$ "never" to $5=$ "always". 
The DMSQ was developed using the concept mapping technique (Rosas \& Camphausen, 2007) with reference to published literature (Rudmin, 2009; Tomas-Sabado et al., 2007). Initiated by the lead author, we first developed the overall conceptual framework of domestic migration stress and its four subconstructs (e.g., Separation, Rejection, Confidence, and Maladaptation) through literature review, theoretical analysis and group discussion. Guided by the established conceptual framework, the lead author drafted 32 items with 8 items per subconstruct. Among the 32 items, 11 were derived from the Barcelona Immigration Stress Scale (Tomas-Sabado et al., 2007) and other 21 were developed by us. These draft items were then circulated among the team members and other faculties $(n=5)$ and graduate students $(\mathrm{n}=8)$ for feedback and revision to form a pilot version. The pilot version of DMSQ included 20 items in total with 5 items per subconstruct. It was tested among rural-to-urban migrants in China $(n=12)$. One item from each of the four subconstructs that was poorly correlated with total scale scores was removed, yielding the finalized 16-item DMSQ.

\subsection{Data Collection}

Data were collected in a designated room at Wuhan CDC using the Migration and Behavioral Health Survey (MBHS) (Chen, Stanton, Gong, Fang, \& Li, 2009; Chen et al., 2009).Participants complete the survey on computer using the Audio Computer-Assisted Self-Interviewing (ACASI) technique. The MBHS took approximately 45 minutes for a typical migrant participant to complete. Before the survey, the signed informed consent forms were collected. Trained data collectors (including two senior staffs from Wuhan CDC and three graduate students with a public health major) were responsible for participant recruitment and questionnaires administration. To ensure the confidentiality and privacy, participants were asked to complete the survey independently in a private room or a place of their preference. The survey was anonymous.

The survey protocol was approved by the Institutional Review Board at Wuhan CDC in China and Human Investigation Committee at Wayne State University in the United States (for data collection), and the Institutional Review Board at University of Florida, the United States (for data analysis).

\subsection{Variable for Assessing Validity}

Perceived global stress: To assess criterion validity, the 10-item Perceived Stress Scale (PSS) (Cohen, Kamarck, \& Mermelstein, 1983; S Cohen \& Williamson, 1988) was used. PSS, although short, has been found to be reliable (Cronbach alpha ranging from .80-.87) (Cohen et al., 1983; Hewitt, Flett, \& Mosher, 1992; Remor, 2006) and has been widely used in research to assess stress (Cohen, 1988; Cole, 1999; Roberti, Harrington, \& Storch, 2006). This scale assesses stressful events a person may experience in daily life in the past month, including the feeling of being unable to control the important things in life, unable to cope with all the things a person has to do, and feeling nervous and/or "stressed"(Cohen et al., 1983; Cohen \& Williamson, 1988). A 5-point Likert scale was used for item scoring with $1=$ "never" to 5= "always". Cronbach alpha was 0.95 for current study. Total scores were calculated for use in analysis such that larger scores indicating higher levels of stress. If the DMSQ is valid, participants scoring high on DMSQ should score high on PSS. Therefore a positive association between the two measures was expected and would be evidence to support acceptable criterion validity of the newly developed DMSQ. 


\subsection{Variables for Assessing the Predictive Validity}

General health status: It has been well documented that stress is associated with a number of psychosomatic problems (Hovey, Magaña, \& Booker, 2003; Wong \& Song, 2008). We used five Brief Symptom Inventory (BSI) subscales (Derogatis \& Melisaratos, 1983) to assess the validity of DMSQ, including Depression (Cronbach alpha=.88), Anxiety (Cronbach alpha=.88), Somatization (Cronbach alpha=.89), Hostility (Cronbach alpha=.86) and Obsessive-Compulsive (Cronbach alpha $=.83$ ). The BSI has excellent reliability (Cheng, Leong, \& Geist, 1993) and has been widely used in research (Wong \& Song, 2008). BSI assesses the frequency of various symptoms experienced by participants using a 5-point Likert scale ( $1=$ "never" and 5 = "always"). Total scores for each of the five domains were used for analysis. A significant positive association between these five variables and the DMSQ scores was used as evidence supporting the validity of the DMSQ.

\subsection{Demographic Variables}

Demographic variables were gender (male/female), age in years, marital status (married/unmarried), educational attainment (middle school or less, high school, college or more), and monthly income (Chinese Yuan, $<1000,1000-2000,>2000$ ). These variables were used to describe the study sample. Relevant variables were selected to assess the construct validity of DMSQ. Data from previous studies suggest that male gender, older age, lower education, and being married are positively associated with stress in migrant populations (Berry, 1997; Eustace, 2007; Park \& Rubin, 2012).

\subsection{Statistical Analysis}

To psychometrically assess the developed DMSQ, item response was assessed with descriptive parameters (e.g. mean, standard deviation). The reliability was measured with correlation analysis, including item-total correlation and Cronbach alpha. The proposed factor structure was verified with confirmatory factor analysis (CFA). When conducting CFA, the following indexes and criteria were used to assess data-model fit: GFI $>.90$, CFI $>.90$, RMSEA $<.05$, Chi-sq $/ \mathrm{df}<2.0$.

Criterion validity was assessed by associating DMSQ scores with PSS scores using correlational analysis. Construct validity was measured by contrasts of the DMSQ scores across levels of several key demographic variables using Student t-test (for dichotomous variables such as gender) and ANOVA (for multi-category variables such as educational attainment). Concurrent predictive validity was evaluated by relating DMSQ scores with other variables using the linear regression analysis. In evaluating concurrent predictive validity, the DMSQ score was used as the independent variable. To more rigorously judge the validity of DMSQ, multiple regression method was used to include age and gender as covariates. Type I error was set at $\mathrm{p}<.05$ (two-sided) for the all psychometric assessment analyses. Statistical analyses were conducted with SAS 9.3 (SAS Institute, Cary, NC).

\section{Results}

\subsection{Characteristics of the Study Sample}

Results in Table 1 indicate that among the 77 participants, 26 (33.77\%) were male and 58 $(75.32 \%)$ were unmarried. The mean age of the sample was $24.34(\mathrm{SD}=5.85)$ years old. 


\section{Macrothink}

Journal of Social Science Studies

ISSN 2329-9150

2015, Vol. 2, No. 2

Table 1. Characteristic of the study sample

\begin{tabular}{llll}
\hline Variables & Male & Female & Total \\
\hline $\begin{array}{l}\text { Total, n (\%) } \\
\text { Age (in years) }\end{array}$ & $26(33.77)$ & $51(66.23)$ & $77(100.00)$ \\
$\quad$ Mean (SD) & $24.23(5.32)$ & $24.39(6.15)$ & $24.34(5.85)$ \\
Marital status, n (\%) & & & \\
$\quad$ Unmarried & $21(80.77)$ & $37(72.55)$ & $58(75.32)$ \\
$\quad$ Married & $5(19.23)$ & $14(27.45)$ & $19(24.68)$
\end{tabular}

Educational attainment, $\mathrm{n}(\%)$

Middle school or less

$6(23.08)$

$10(19.61)$

$16(20.78)$

High school

$11(42.30)$

$30(58.82)$

$41(53.25)$

College or higher

9 (34.62)

$11(21.57)$

$20(25.97)$

Monthly income (RMB), n (\%)

$<1000$ Yuan

$5(20.00)$

7 (14.89)

$12(16.67)$

1000-2000 Yuan

$11(44.00)$

$31(65.96)$

$42(58.33)$

$>2000$ Yuan

$9(36.00)$

$9(19.15)$

$18(25.00)$

Perceived stress

Mean (SD)

$28.31(3.39) \quad 28.12(2.94) \quad 28.18(3.08)$

BSI scores, mean (SD)

Depression

$10.69(3.50) \quad 10.45(3.74)$

$10.53(3.64)$

Anxiety

$12.08(3.46) \quad 11.98(4.06)$

$12.01(3.85)$

Somatization

$13.27(8.86) \quad 13.02(4.50)$

$13.10(4.27)$

Hostility

11.35 (3.30)

11.41 (3.97)

$11.39(3.74)$

Obsessive-compulsive

$13.42(3.38) \quad 13.63(4.21)$

$13.56(3.93)$

\subsection{Item Response}

Results in Table 2 indicated that the item mean scores varied around the theoretical mean of 3.0 , and the item-total correlation coefficients ranged from .44 to .82 . 
Table 2. The Domestic Migration Stress Questionnaire (DMSQ) (alpha=0.93)

\begin{tabular}{llll}
\hline Items by subconstruct & $\begin{array}{l}\text { Mean } \\
\text { (SD) }\end{array}$ & $\begin{array}{l}\text { r with Alpha if } \\
\text { total }\end{array}$ & \begin{tabular}{l} 
deleted \\
\hline
\end{tabular} \\
\hline
\end{tabular}

Separation from the place of origin (alpha=.77)

1.Craving for family members, relatives and $2.62(.99) \quad .44$

friends from my hometown to come and visit.

2. Worried so much about my family members and $2.87(1.09) \quad .56$

relatives who remain so far away in hometown*.

$\begin{array}{llllll}3 . \text { Very frustrating when I miss my family but } 2.34(.95) & .74\end{array}$ unable to go back and visit them*.

4.Missing so much about the freedom and the $2.61(1.13) \quad .75$

familiar daily life in my hometown*.

Rejection in the destination(alpha=.86)

$\begin{array}{llll}5 . \text { Being rejected or stared at by others in the city } 2.18(1.00) & .72\end{array}$ merely because of my appearance or accent*.

6. No matter what I do, I cannot change the fact that $2.16(.99) \quad .64$

I am a migrant.

7.Always being treated as the second class citizen.

$2.00(.93) \quad .73$

8. No option but to take the inferior jobs*.

$2.00(.92) \quad .68$

Lack of self-confidence(alpha $=.70)$

9.Unconfident about my own capabilities.

10.As if unexpected things will happen anytime*.

11. Would never get rich no matter how hard I try *.

$2.09(1.00) \quad .63$

12.How to face the new and complicated urban environment presents a big challenge.

Maladaptation (alpha=.90)

13.Did not expect that it was so difficult to make $2.58(1.16) \quad .82$ money here*.

14.Most things did not go as planned*.

15.Nothing here is the same as I thought of before I $2.39(.89) \quad .78$ came.

16.So many rules and regulations in the city make $2.10(.91) \quad .72$ .93 me like to crush*.

Note: *: Items derived from the Barcelona Immigration Stress Scale (Tomas-Sabado et al., 2007). 


\subsection{Factor Structure}

Results from CFA in Figure 1 indicate that the proposed two-level and four-subconstruct structural DMS model fit the data well (GFI=.91, CFI=.99, RMSEA=.03, Chi-square/df=1.08.). For each latent subconstruct, the observed items were all related to the subconstruct, and the four latent subconstructs in turn were all related to the single latent construct "domestic migration stress", with model coefficients ranging from 0.79 to 0.996 .

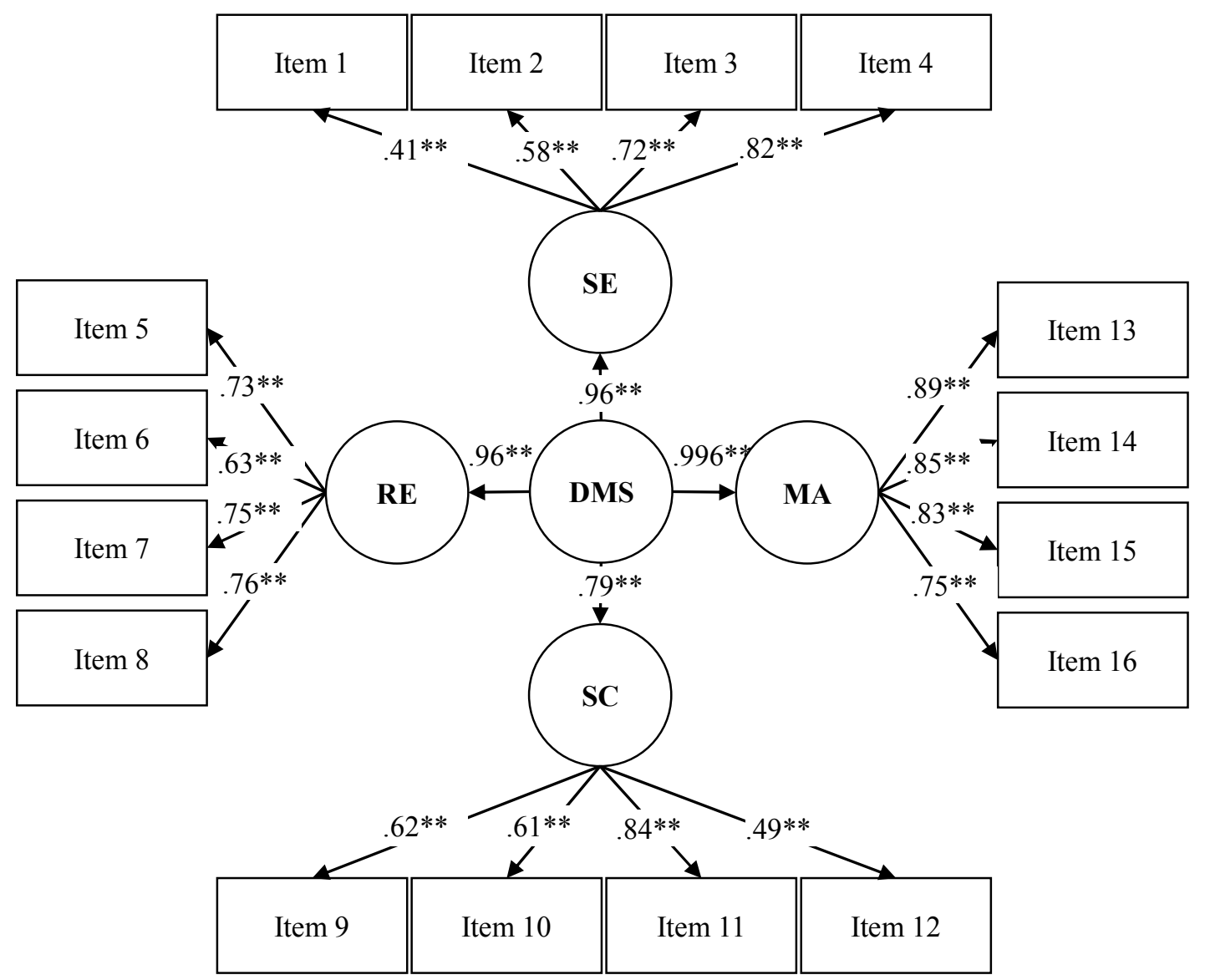

Figure 1. Measurement Modeling/CFA of the Domestic Migration Stress Questionnaire (DMSQ) Note: DMS: Domestic migration stress, SE: Separation from the origin, RE: Rejection in the destination; SC: Lack of self-confidence; and MA: Maladaptation.

Data-model fit: GFI=.91, CFI=.99, RMSEA=.03 and Chi-square/df=1.08.

\subsection{Reliability}

Cronbach alpha coefficients of the DMSQ and its four subconstructs for various subgroups are presented in Table 3. The alpha was .93 for DMSQ, and .77, .86, .70, .90 for the subconstructs $\mathrm{SE}, \mathrm{RE}, \mathrm{SC}$, and MA respectively. 
Table 3. Cronbach's Alpha of the Domestic Migration Stress Questionnaire (DMSQ) and its four subconstructs, Overall and by subsamples

\begin{tabular}{lllllll}
\hline \multirow{2}{*}{ Category } & \multirow{2}{*}{ N } & \multicolumn{6}{c}{ Cronbach's alpha coefficient } \\
\cline { 2 - 7 } & & DMSQ & SE & RE & SC & MA \\
\hline Total sample & 77 & .93 & .77 & .86 & .70 & .90
\end{tabular}

\section{Gender}

$\begin{array}{lcccccc}\text { Male } & 26 & .95 & .86 & .94 & .82 & .93 \\ \text { Female } & 51 & .92 & .72 & .77 & .63 & .88 \\ \text { Chronological age } & & & & & & \\ \text { Less than 30 years } & 63 & .94 & .79 & .84 & .74 & .88 \\ \text { 30 years or older } & 14 & .91 & .64 & .90 & .50 & .95\end{array}$

\section{Educational attainment}

$\begin{array}{lcccccc}\text { Middle school or less } & 16 & .97 & .86 & .91 & .88 & .94 \\ \text { High school } & 41 & .89 & .60 & .86 & .52 & .88 \\ \text { College or more } & 20 & .94 & .87 & .72 & .77 & .86\end{array}$

Note: DMSQ: the Domestic Migration Stress Questionnaire; SE: Separation from the origin, RE: Rejection in the destination; SC: Lack of self-confidence; and MA: Maladaptation.

\subsection{Criterion Validity}

Results in the second column of Table 4 indicate that the DMSQ scores were significantly correlated with PSS scores $(r=.41, \mathrm{p}<.01)$. Consistent with this results, the scores for the four subconstructs each were significantly correlated with the PSS scores with Pearson correlation coefficient $r$ varying from .27 (for $\mathrm{SE}, \mathrm{p}<.05$ ) to .45 (for $\mathrm{SC}, \mathrm{p}<.01$ ), indicating high criterion-related validity of this new tool.

\subsection{Concurrent Predictive Validity}

Results in the column three to column seven in Table 4 indicate that DMSQ positively and significantly predicted all five BSI subscales at $\mathrm{p}<.01$ level. With a one point increase in the DMSQ scores, there were respectively, a .18-point increase in the Depression score, .2-point increase in the Anxiety score and the Obsessive/Compulsive score and a .14-point increase in the Somatization score and .15-point increase in the Hostility score. Likewise, the four DMSQ subconstructs each significantly predicted the five BSI subscale scores. Among the four subconstructs, the regression coefficients were ranging from .34 to .71 . These results indicated high concurrent predictive validity of the new instrument. 


\section{Macrothink}

Journal of Social Science Studies

ISSN 2329-9150

2015, Vol. 2, No. 2

Table 4. The Relationship between the Domestic Migration Stress Questionnaire and the six variables for assessing validity $(\mathrm{N}=77)$

\begin{tabular}{|c|c|c|c|c|c|c|}
\hline \multirow[b]{2}{*}{ Variables } & \multirow{2}{*}{$\begin{array}{l}\text { Perceived } \\
\text { Stress }^{1}\end{array}$} & \multicolumn{5}{|c|}{ Health-related symptoms from BSI $^{2}$} \\
\hline & & Depression & Anxiety & Somatization & Hostility & $\begin{array}{l}\text { Obsessive- } \\
\text { compulsive }\end{array}$ \\
\hline DMSQ scale & $.41 * *$ & $.18 * *$ & $.20 * *$ & $.14 * *$ & $.15^{* *}$ & $.20 * *$ \\
\hline \multicolumn{7}{|l|}{ Subconstruct } \\
\hline SE & $.27^{*}$ & $.46^{* *}$ & $.47 * *$ & .28 & $.34^{*}$ & $.54 * *$ \\
\hline $\mathrm{RE}$ & $.38 * *$ & $.59 * *$ & $.71 * *$ & $.54 * *$ & $.53 * *$ & $.58 * *$ \\
\hline $\mathrm{SC}$ & $.45^{* *}$ & $.53 * *$ & $.59 * *$ & $.43^{*}$ & $.45^{*}$ & $.59 * *$ \\
\hline MA & $.35^{*}$ & $.65^{* *}$ & $.65^{* *}$ & $.50^{* *}$ & $.53 * *$ & $.71^{* *}$ \\
\hline
\end{tabular}

Note:

(1) DMSQ: The Domestic Migration Stress Questionnaire; SE: Separation from the origin, RE: Rejection in the destination; SC: Lack of self-confidence; and MA: Maladaptation. BSI: The Brief Symptoms Inventory.

(2) ${ }^{1}$ Pearson correlation coefficients and ${ }^{2}$ Linear regression coefficients predicting the two identification and five symptom variables with age and gender included as covariates in the regression analysis.

(3) $* * \mathrm{P}<.001, * \mathrm{P}<.05$.

\subsection{Construct Validity}

Results in Table 5 indicate that migrants who were male, older, received less education, and were married appeared to score higher on DMSQ. These results suggest this new measurement tool may have certain construct validity. 
Table 5. Difference of Domestic Migration Stress between Gender, Age, Education, Marital Status: Construct validity $(\mathrm{N}=77)$

\begin{tabular}{lllllll}
\hline Variables & N & DMSQ & SE & RE & SC & MA \\
\hline Gender & & & & & & \\
Male & 26 & $38.35(12.49)$ & $10.27(3.48)$ & $9.12(3.83)$ & $9.19(3.20)$ & $9.77(3.63)$ \\
Female & 51 & $37.04(10.33)$ & $10.53(3.07)$ & $7.94(2.80)$ & $9.41(2.65)$ & $9.16(3.21)$ \\
Age in years & & & & & & \\
$<30$ years & 63 & $36.83(10.92)$ & $10.25(3.20)$ & $8.06(2.98)$ & $9.30(2.90)$ & $9.25(3.16)$ \\
$\geq 30$ years & 14 & $40.21(11.60)$ & $11.29(3.15)$ & $9.57(3.99)$ & $9.50(2.59)$ & $9.86(4.20)$ \\
Education & & & & & & \\
$\leq$ Middle school & 16 & $37.00(13.96)$ & $9.69(3.55)$ & $8.25(3.45)$ & $9.75(3.59)$ & $9.31(4.21)$ \\
High school & 41 & $39.51(9.56)$ & $11.10(2.74)$ & $8.95(3.32)$ & $9.49(2.41)$ & $9.98(3.09)$ \\
College or more & 20 & $33.70(10.83)$ & $9.70(3.63)$ & $7.15(2.52)$ & $8.70(3.01)$ & $8.15(2.89)$ \\
Marital status & & & & & & \\
Unmarried & 58 & $36.48(11.28)$ & $10.33(3.35)$ & $7.98(3.33)$ & $8.98(2.89)$ & $9.19(3.29)$ \\
Married & 19 & $40.53(9.95)$ & $10.79(2.72)$ & $9.42(2.61)$ & $10.42(2.39)$ & $9.89(3.56)$ \\
\hline
\end{tabular}

Note: DMSQ: The Domestic Migration Stress Questionnaire; SE: Separation from the origin, RE: Rejection in the destination; SC: Lack of self-confidence; and MA: Maladaptation.

\section{Discussion and Conclusions}

In this study, we reported our work in developing and evaluating the Domestic Migration Stress Questionnaire (DMSQ), a new instrument specifically designed to assess levels of stress associated with domestic migration. The scale was developed through a team effort, and evaluated with data collected from a convenience sample of rural migrants in China. The finalized version of the scale is short (16 items) and consists of four subconstructs (a) separation from the place of origin, (b) rejection in the destination, (c) lack of self-confidence, and (d) maladaptation.

Results from psychometric assessment indicated adequate validity and reliability of the DMSQ, and thus its utility for use in future research evaluating stress associated with domestic migration. The 16 DMSQ items were developed using the concept mapping method, ensuring adequate face validity. The factor structure of the scale was verified using the rigorous CFA method. The Cronbach alpha coefficients were .93 for DMSQ, and $.77, .86, .70, .90$ for the four subconstructs respectively. The DMSQ was significantly positively correlated with the Perceived Stress Scale, indicating adequate criterion-related validity. The scale scores were also significantly associated with five BSI health status measures (e.g., depression, anxiety, somatization, hostility and obsessive-compulsive), suggesting predictive validity. 
Although a number of instruments have been developed to assess stresses associated international and cross-country migration (Jibeen \& Khalid, 2010; Rodriguez et al., 2002; Tomas-Sabado et al., 2007), the DMSQ will be the first for measuring stress associated with domestic migration. It provides a tool much needed to investigate health issues related to domestic migration. In the era when the rapid economic growth characterizes the main part of the development in almost all countries across the globe (Burns, 2013), we cannot ignore health issues associated with domestic migration given the large number of domestic migrant population and their roles in economic growth and development. Such issues are particularly pressing in many rapid growing countries, such as China (Aunan \& Wang, 2014; Shen, 1995) and India (Becker, Mills, \& Williamson, 1986; Sinha, 2013). We anticipate that the provision of the DMSQ may also facilitate the investigation of behavioral and health issues among domestic migrants in other countries and regions outside of China.

\section{Limitations and Further Research}

The DMSQ was evaluated with data from one city in China. The reliability and validity of the instrument in other cities within China and cities in other countries outside of China cannot be determined without further research. In addition, the evaluation of the DMSQ was based on data from a cross-sectional survey. Psychometric characteristics including prospective predictive validity and test re-test reliability cannot be determined without longitudinal data. Lastly, none of the between-group differences for construct validity assessment reached to the statistical significance at $\mathrm{p}<.05$ level due to a relatively small sample size. This issue also needs to be addressed in future research. Despite these limitations, research findings of this study demonstrates that the DMSQ, although brief, is reliable and valid for assessing the perceived stress among domestic migrants moving from rural areas and living and earning money in urban settings.

\section{Acknowledgement}

This work was supported through a research grant from the National Institute of Health (Award \#: R01 MH086322). We are very grateful to other researchers and community health workers who participated in data collection and data processing. This work will not be possible without their dedicated efforts and general assistance.

\section{Reference}

Al-Rodhan, N. R. F., \& Stoudmann, G. (2006). Definitions of globalization: A comprehensive overview and a proposed definition: Geneva Centre for Security Policy.

Aroian, K. J., Norris, A. E., Tran, T. V., \& Schappler-Morris, N. (1998). Development and psychometric evaluation of the Demands of Immigration Scale. Journal of Nursing Measurement, 6(2), 175-194.

Aunan, K., \& Wang, S. (2014). Internal migration and urbanization in China: Impacts on population exposure to household air pollution (2000-2010). [Research Support, Non-U.S. Gov't]. The Science of the Total Environment, 481, 186-195. http://dx.doi.org/10.1016/j.scitotenv.2014.02.073

Becker, C. M., Mills, E. S., \& Williamson, J. G. (1986). Dynamics of rural-urban migration in India: 1960-1981. Indian Journal of Quantitative Economics, 2(1), 1-43.

Berry, J. W. (1997). Immigration, acculturation, and adaptation. Applied Psychology: An 
International Review, 46(1), 5-34. http://dx.doi.org/10.1111/j.1464-0597.1997.tb01087.x

Berry, J. W., Phinney, J. S., Sam, D. L., \& Vedder, P. (2006). Immigrant youth: Acculturation,identity and adaptation. Applied Psychology: An International Review, 55(3), 303-332. http://dx.doi.org/10.1111/j.1464-0597.2006.00256.x

Burns, A. (2013). Global economic prospects assuimg growth over the medium term. Retrieved 07/28, 2014, from http://siteresources.worldbank.org/INTWBEUROPE/Resources/GEP_2013_Road_Show_Bru ssels.pdf

Cavazos-Rehg, P. A., Zayas, L. H., Walker, M. S., \& Fisher, E. B. (2006). Evaluating an abbreviated version of the Hispanic stress inventory for immigrants. Hispanic Journal of Behavioral Sciences, 28(4), 498-515. http://dx.doi.org/10.1177/0739986306291740

Chen, X. (2014). Understanding the development and perception of global health for more effective student education. Yale Journal of Biology and Medicine, 87(3), 231.

Chen, X., Li, X., Stanton, B., Fang, X., Lin, D., Cole, M., ... Yang, H. (2004). Cigarette smoking among rural-to-urban migrants in Beijing, China. [Research Support, Non-U.S. Gov't Research Support, U.S. Gov't, P.H.S.]. Preventive Medicine, 39(4), 666-673. http://dx.doi.org/10.1016/j.ypmed.2004.02.033

Chen, X., Stanton, B., Gong, J., Fang, X., \& Li, X. (2009). Personal Social Capital Scale: an instrument for health and behavioral research. Health Education Research, 24(2), 306-317. http://dx.doi.org/10.1093/her/cyn020

Chen, X., Stanton, B., Li, X., Fang, X., \& Lin, D. (2008). Substance use among rural-to-urban migrants in China: A moderation effect model analysis. [Research Support, N.I.H., Extramural Research Support, Non-U.S. Gov't]. Substance Use \& Misuse, 43(1), 105-124. http://dx.doi.org/10.1080/10826080701209077

Chen, X., Stanton, B., Li, X., Fang, X., Lin, D., \& Xiong, Q. (2009). A comparison of health-risk behaviors of rural migrants with rural residents and urban residents in China. [Comparative Study Research Support, N.I.H., Extramural]. American Journal of Health Behavior, 33(1), 15-25. http://dx.doi.org/10.5993/AJHB.33.1.2

Cheng, D., Leong, F. T., \& Geist, R. (1993). Cultural differences in psychological distress between Asian and Caucasian American college students. Journal of Multicultural $\begin{array}{llll}\text { Counseling and } \quad \text { Development, } & \text { 21(3), }\end{array}$ http://dx.doi.org/10.1002/j.2161-1912.1993.tb00598.x

Cohen, S. (1988). Perceived stress in a probability sample of the United States. Newbury Park, CA, Sage.

Cohen, S., Kamarck, T., \& Mermelstein, R. (1983). A global measure of perceived stress. Journal of health and social behavior, 385-396. http://dx.doi.org/10.2307/2136404

Cohen, S., \& Williamson, G. (1988). Perceived stress in a probability sample of the United States. Newbury Park, CA: Sage.

Cole, S. R. (1999). Assessment of differential item functioning in the Perceived Stress Scale-10. Journal of Epidemiology and Community Health, 53(5), 319. http://dx.doi.org/10.1136/jech.53.5.319 
De Haan, A. (1997). Migration as family strategy: Rural-urban labor migration in India during the twentieth century. The History of the Family : An International Quarterly, 2(4), 481-505. http://dx.doi.org/10.1016/S1081-602X(97)90026-9

Derogatis, L. R., \& Melisaratos, N. (1983). The brief symptom inventory: an introductory report. Psychological medicine, 13(03), 595-605. http://dx.doi.org/10.1017/S0033291700048017

Eustace, R. W. (2007). Factors influencing acculturative stress among international students in the United States. Kansas State University.

Gui, Y., Berry, J. W., \& Zheng, Y. (2012). Migrant worker acculturation in China. International Journal of Intercultural Relations, 36(4), 598-610. http://dx.doi.org/10.1016/j.ijintrel.2011.11.007

Hewitt, P. L., Flett, G. L., \& Mosher, S. W. (1992). The Perceived Stress Scale: Factor structure and relation to depression symptoms in a psychiatric sample. Journal of Psychopathology and Behavioral Assessment, 14(3), 247-257. http://dx.doi.org/10.1007/BF00962631

Hovey, J. D., Magaña, C., \& Booker, V. (2003). The relationship of migrant farmwork stress to depression and hopelessness: Preliminary findings in the standardization of the Migrant Farmworker Stress Inventory (MFWSI). The Program for the Study of Immigration and Mental Health, The Department of Psychology, The University of Toledo: Toledo, Ohio.

Jibeen, T., \& Khalid, R. (2010). Development and Preliminary Validation of Multidimensional Acculturative Stress Scale for Pakistani Immigrants in Toronto, Canada. International Journal of Intercultural Relations, 34(3), 233-243. http://dx.doi.org/10.1016/j.ijintrel.2009.09.006

Lin, D., Li, X., Yang, H., Fang, X., Stanton, B., Chen, X., ... Liu, H. (2005). Alcohol intoxication and sexual risk behaviors among rural-to-urban migrants in China. [Research Support, N.I.H., Extramural Research Support, U.S. Gov't, P.H.S.]. Drug and Alcohol Dependence, 79(1), 103-112. http://dx.doi.org/10.1016/j.drugalcdep.2005.01.003

Ma, Z., Liaw, K. L., \& Zeng, Y. (1997). Migration in the urban-rural hierarchy of China: insights from the microdata of the 1987 National Survey. Environment \& Planning A, 29(4), 707-730. http://dx.doi.org/10.1068/a290707

National Statistical Bureau. (2012). National rural-to-urban migrants surveillance report in 2011 Retrieved July $11, \quad 2014$, from http://www.stats.gov.cn/ztjc/ztfx/fxbg/201204/t20120427_16154.html

Park, H.-S., \& Rubin, A. (2012). The mediating role of acculturative stress in the relationship between acculturation level and depression among Korean immigrants in the U.S. International Journal of Intercultural Relations, 36(5), 611-623. http://dx.doi.org/10.1016/j.ijintrel.2012.04.008

Ramirez, F. P., Garcia-Garcia, I., \& Peralta-Ramirez, M. I. (2013). The Migration Process as a Stress Factor in Pregnant Immigrant Women in Spain. Journal of Transcultural Nursing, 24(4), 348-354. http://dx.doi.org/10.1177/1043659613493328

Remor, E. (2006). Psychometric properties of a European Spanish version of the Perceived 
Stress Scale (PSS). The Spanish journal of psychology, 9(01), 86-93. http://dx.doi.org/10.1017/S1138741600006004

Roberti, J. W., Harrington, L. N., \& Storch, E. A. (2006). Further psychometric support for the 10 - Item Version of the Perceived Stress Scale. Journal of College Counseling, 9(2), 135-147. http://dx.doi.org/10.1002/j.2161-1882.2006.tb00100.x

Rodriguez, N., Myers, H. F., Mira, C. B., Flores, T., \& Garcia-Hernandez, L. (2002). Development of the Multidimensional Acculturative Stress Inventory for adults of Mexican origin. Psychological Assessment, $14(4), \quad$ 451-461. http://dx.doi.org/10.1037//1040-3590.14.4.451

Rosas, S. R., \& Camphausen, L. C. (2007). The use of concept mapping for scale development and validation in evaluation. Evaluation and Program Planning, 30(2), 125-135. http://dx.doi.org/10.1016/j.evalprogplan.2007.01.003

Rudmin, F. (2009). Constructs, measurements and models of acculturation and acculturative stress. International Journal of Intercultural Relations, 33(2), 106-123. http://dx.doi.org/10.1016/j.ijintrel.2008.12.001

Sanou, D., O'Reilly, E., Ngnie-Teta, I., Batal, M., Mondain, N., Andrew, C., ... Bourgeault, I. L. (2014). Acculturation and nutritional health of immigrants in Canada: a scoping review. [Research Support, Non-U.S. Gov't]. Journal of Immigrant and Minority Health, 16(1), 24-34. http://dx.doi.org/10.1007/s10903-013-9823-7

Shen, J. (1995). Rural development and rural to urban migration in China 1978-1990. Geoforum, 26(4), 395-409. http://dx.doi.org/10.1016/0016-7185(95)00044-5

Sinha, K. (2013). Mass economic migration: the greatest threat to HIV control in India. [Review]. BMJ, 346, f474. http://dx.doi.org/10.1136/bmj.f474

Sirin, S. R., Ryce, P., Gupta, T., \& Rogers-Sirin, L. (2013). The role of acculturative stress on mental health symptoms for immigrant adolescents: a longitudinal investigation. Developmental Psychology, 49(4), 736-748. http://dx.doi.org/10.1037/a0028398

Statistical Bureau of Wuhan. (2012). Wuhan Statistical Yearbook-2012. Beijing: China Statistics Press.

Tomas-Sabado, J., Qureshi, A., Antonin, M., \& Collazos, F. (2007). Construction and preliminary validation of the Barcelona Immigration Stress Scale. Psychological Reports, 100(3 Pt 1), 1013-1023. http://dx.doi.org/10.2466/pr0.100.3.1013-1023

van der Ham, A. J., Ujano-Batangan, M. T., Ignacio, R., \& Wolffers, I. (2014). Toward healthy migration: An exploratory study on the resilience of migrant domestic workers from the Philippines. Transcultural Psychiatry, 51(4), 545-568. http://dx.doi.org/10.1177/1363461514539028

Wong, D. F. K., \& Chang, Y.-L. (2010). Mental health of Chinese migrant workers in factories in Shenzhen, China: Effects of migration stress and social competence. Social Work in Mental Health, 8(4), 305-318. http://dx.doi.org/10.1080/15332980903217768

Wong, D. F. K., Lam, D., Yan, P., \& Hung, M. (2004). The impacts of acculturative stress and social competence on the mental health of Mainland Chinese immigrant youth in Hong Kong. British Journal of Social Work, 34(7), 1009-1024. http://dx.doi.org/10.1093/bjsw/bch126 


\section{Macrothink}

Journal of Social Science Studies

ISSN 2329-9150

2015, Vol. 2, No. 2

Wong, D. F. K., \& Song, H. X. (2008). The resilience of migrant workers in Shanghai China: the roles of migration stress and meaning of migration. International Journal of Social Psychiatry, 54(2), 131-143. http://dx.doi.org/10.1177/0020764007083877

$\mathrm{Xu}, \mathrm{D}$. (2006). The research of criminal condition in the migrant population in Wuhan Retrieved July 7, 2014, from http://www.wuhanass.org.cn/news/200964/n1101193.html

Yadava, K. N. (1987). Determinants of rural-urban migration in India: A micro approach. Rural Demography, 14(1-2), 1-20.

Yang, B., \& Clum, G. A. (1994). Life Stress, Social Support, and Problem - Solving Skills Predictive of Depressive Symptoms, Hopelessness, and Suicide Ideation in an Asian Student Population: A Test of a Model. Suicide and Life-Threatening Behavior, 24(2), 127-139.

Yu, B., Chen, X., \& Li, S. (2013). Globalization, Cross-Culture Stress and Health. Chinese Journal of Epidemiology 35(3), 338-341.

Yu, B., Chen, X., Li, S., Liu, Y., Jacques-Tiura, A. J., \& Yan, H. (2014). Acculturative Stress and Influential Factors among International Students in China: A Structural Dynamic Perspective. PloS one, 9(4), e96322. http://dx.doi.org/10.1371/journal.pone.0096322

\section{Copyright Disclaimer}

Copyright reserved by the author(s).

This article is an open-access article distributed under the terms and conditions of the Creative Commons Attribution license (http://creativecommons.org/licenses/by/3.0/). 